\title{
Influence of electrode geometry on the lightning impulse breakdown voltage of palm oil
}

\begin{abstract}
This paper presents a study of lightning impulse breakdown voltage of palm oil under needle/plane and needle/sphere electrode configurations. All tests were carried out at gap distance of $25 \mathrm{~mm}$ under both positive and negative polarities. Two types of palm oil and mineral oil were used in this study. The results show that the different electrode geometry has significant impact on the lightning impulse breakdown voltage. It was found that needle/plane geometry has lower breakdown voltage than needle/sphere. The voltage polarity also showed some influence on the lightning breakdown voltage for all fluid samples. Comparing both positive and negative polarities, the percentage of difference between all samples is much higher under needle/plane electrode configuration which can be up to $43 \%$. The positive mean lightning breakdown voltage of palm oil is comparable with the mineral oil.
\end{abstract}

Keyword: Electrode geometry; Lightning impulse breakdown voltage; Palm oil; Transformer 